\title{
Rapid Conversion to High Xanthine Oxidase Activity in Viable Kupffer Cells during Hypoxia
}

Jeffrey S. Wiezorek, Douglas H. Brown, David E. Kupperman, and Clifford A. Brass

Gastroenterology Division, Department of Medicine and Department of Biochemistry and Biophysics, University of Pennsylvania School of Medicine, and the Philadelphia Veterans Administration Hospital, Philadelphia, Pennsylvania 19104

\begin{abstract}
It has been widely postulated that the central mechanism of hepatic reperfusion injury involves the conversion, during ischemia, of the enzyme xanthine dehydrogenase (XDH) to its free radical-producing form, xanthine oxidase (XOD). However, this theory has been questioned because $(a)$ XDH to XOD conversion in whole liver occurs very slowly; $(b)$ the cellular distribution of XDH/XOD is unclear; and (c) the direct demonstration of XDH to XOD conversion in viable cells is lacking. In this paper, we address all three issues by measuring XDH to XOD conversion and cell viability in purified populations of hepatic endothelial cells (EC), Kupffer cells (KC), and hepatocytes (HEP). Although $\mathrm{XDH} / \mathrm{XOD}$ activity on a cellular basis was greater in hepatocytes $\left(0.92 \pm 0.12 \mathrm{mU} / 10^{6}\right.$ cells $)$ than ECs $(0.03 \pm 0.01)$ or KCs (0.12 \pm 0.04$),$ XDH + XOD specific activity was similar in all three cell types (HEP $1.85 \pm 0.10 \mathrm{U} / \mathrm{g}$ protein; EC $1.69 \pm 0.54 ; \mathrm{KC} 2.30 \pm 0.22)$. Over $150 \mathrm{~min}$ of warm $\left(37^{\circ} \mathrm{C}\right)$ or $24 \mathrm{~h}$ of cold $\left(4^{\circ} \mathrm{C}\right)$ hypoxia, percent XOD activity increased slowly in ECs, from $21 \pm 2 \%$ (basal) to $39 \pm 3 \%$ (warm) and $49 \pm 5 \%$ (cold) and in HEPs $(29 \pm 2 \%$ to $38 \pm 3 \%$ and $49 \pm 2 \%$ ), but converted significantly faster in KCs $(28 \pm 3 \%$ to $91 \pm 7 \%$ and $94 \pm 4 \%$ ). The dramatic changes in Kupffer cell XOD during cold hypoxia occurred despite only minor changes in cell viability. When hypoxic KCs were reoxygenated after $16 \mathrm{~h}$ of cold hypoxia, there was a marked increase in cell death that was significantly blocked by allopurinol. These data suggest that significant conversion to the free radical-producing state occurs within viable $\mathrm{KCs}$, and that Kupffer cell XOD may play an important role in mediating reperfusion injury in the liver. (J. Clin. Invest. 1994. 94:2224-2230.) Key words: xanthine oxidase $\cdot$ Kupffer cell - reperfusion - hypoxia $\bullet$ free radicals
\end{abstract}

\section{Introduction}

With improvements in immunosuppresive and surgical techniques over the last decade, liver transplantation has become

This work was presented in part at Digestive Diseases Week in San Francisco, CA on 10 May 1992 and in Boston, MA on 16 May 1993 and at the American Association for the Study of Liver Disease Meeting in Chicago, IL on 6 November 1993.

Address correspondence to Dr. Clifford A. Brass, Division of Gastoenterology, Clinical Research Building 600, 422 Curie Boulevard, Philadelphia, PA 19104-6144.

Received for publication 9 February 1994 and in revised form 25 August 1994.

The Journal of Clinical Investigation, Inc

Volume 94, December 1994, 2224-2230 an increasingly common and important clinical tool, with over 3,000 operations performed a year in nearly 65 centers in the United States (1). In contrast, the procurement and optimal preservation of donor organs continues to be a major difficulty marked by a $10 \%$ rate of primary graft nonfunction with an even greater level of preservation/reperfusion injury (2). To improve preservation techniques, a keener insight into the mechanisms of ischemic/reperfusion injury is required.

Despite a plethora of research on reperfusion injury in the heart, gut, kidney, and liver, there is little consensus on the key mechanistic elements of this process. However, most researchers agree that oxygen-derived free radicals formed during reperfusion are important elements of this injury. These radicals are believed to be involved in lipid peroxidation (3), protein oxidation (4), and cross-linking (5), and as signals for other injurious processes such as neutrophil chemotaxis (6-8) and concomitant microvascular blockade $(9,10)$.

Perhaps the most prevalent and controversial theory regarding reperfusion injury relates to the role of xanthine oxidase $(\mathrm{XOD})^{1}$ in generating these free radicals. Xanthine dehydrogenase $(\mathrm{XDH})$ is a unique enzyme in that it may undergo both a reversible conformational change, involving the oxidation of several of its 14 sulfhydryl groups, or an irreversible proteolytic cleavage to a smaller species (XODe), both with oxidase activity $(11,12)$. Both XDH and XOD use xanthine or hypoxanthine as substrates, however $\mathrm{XDH}$ uses $\mathrm{NAD}^{+}$as an electron acceptor to form NADH, whereas XOD uses molecular oxygen as an electron acceptor to form the superoxide radical.

In 1983, Roy and McCord (13) published data demonstrating the rapid conversion of XDH to XOD during warm ischemia in a number of excised tissues, including the liver. These results lay the foundation for the XOD theory of reperfusion injury. According to this hypothesis, during ischemia, endogenous, $\mathrm{NAD}^{+}$-dependent $\mathrm{XDH}$ is converted to the oxygen radical-producing form, XOD. Concurrently, there is an accumulation of the reduced substrates hypoxanthine and xanthine from the breakdown of ATP during hypoxia. Upon reoxygenation, XOD reacts with molecular oxygen, the limiting reactant during ischemia, to produce a burst of superoxide radicals which mediate subsequent injurious events. Evidence supporting this role for XOD is primarily indirect, based on the observation that allopurinol, an inhibitor of XOD, is as effective as oxygen radical scavengers in diminishing ischemia/reperfusion-related tissue injury (14-16).

The importance of XOD in reperfusion injury, especially in the liver, remains controversial. The questions regarding this theory center on three major issues: $(a)$ the conversion from

1. Abbreviations used in this paper: EC, endothelial cell; HEP, hepatocyte; KC, Kupffer cell; XDH, xanthine dehydrogenase; XOD, xanthine oxidase; XODc, conformationally altered XOD; XODe, enzymatically cleaved XOD. 
$\mathrm{XDH}$ to XOD appears to occur in a time course too slow to explain reperfusion events $(17-19) ;(b)$ the cellular localization of XOD within the liver is unclear (20); and (c) no definitive demonstration of XDH to XOD conversion in live cells has been made yet.

If the proposed model of reperfusion injury is correct, then $\mathrm{XDH}$ to XOD conversion must occur in a time frame consistent with observed cellular damage. Although there is substantial enzyme conversion during hypoxia, under certain well-defined physiological conditions ( starved rats with cardiopulmonary arrest; 19), several studies investigating XDH to XOD conversion in excised liver suggest that the rate of conversion is incompatible with the purported role of XOD in mediating reperfusion injury $(17,18)$. However, in measuring whole organ activity, changes in XOD levels in the nonparenchymal cells may be missed due to the dominance of hepatocellular protein (>90\%). This problem is of particular concern since recent data now suggest that endothelial cells (ECs) and Kupffer cells (KCs) play a major role in mediating hepatic reperfusion injury (21). In fact, the one major advance in liver preservation has been the use of the University of Wisconsin solution (UW), which acts primarily by decreasing nonparenchymal cell injury $(22,23)$. Several investigators now suggest that hepatic reperfusion injury may be due to $\mathrm{EC}$ and/or $\mathrm{KC}$ free radical production (24-26).

The potential importance of nonparenchymal cell oxyradical production raises the issue of the cellular distribution of XOD/ $\mathrm{XDH}$ in the liver. Histologic studies have produced conflicting data supporting either $\mathrm{EC}(27,28)$ or hepatocellular localization of XOD (29-31). Further blurring its physiological role in reperfusion injury, cytotochemical studies suggest that hepatic XOD resides primarily within the crystalline cores of peroxisomes in the hepatocyte (32).

Most studies demonstrating significant XDH to XOD conversion have been performed in excised tissues. Therefore, the direct demonstration of enzyme conversion within live tissue has been lacking. We have previously demonstrated $\mathrm{XDH}$ to XOD conversion in hypoxically perfused livers which appear viable by their ability to maintain bile production and consume oxygen upon reperfusion (19). However, definitive proof of enzyme conversion within live cells of the organ has remained elusive. In contrast, near complete conversion to XOD is known to occur after cell death (Brass, C. A., and J. L. Gollan, unpublished observations ).

In this paper we address all the issues outlined above by reporting on $\mathrm{XDH}$ to $\mathrm{XOD}$ conversion in purified populations of hepatocytes (HEPs), ECs, and KCs. These studies demonstrate a similar XDH + XOD specific activity in all three cell types. However, conversion from $\mathrm{XDH}$ to $\mathrm{XOD}$, during both warm and cold hypoxia, occurred much faster in KCs than in either HEPs or ECs. High levels of XOD were formed with minimal loss of $\mathrm{KC}$ viability. However, reperfusion injury in KCs was blocked by allopurinol, suggesting that $\mathrm{XDH}$ to $\mathrm{XOD}$ conversion in hypoxic KCs may play an important role in mediating hepatic reperfusion injury.

\section{Methods}

Cell preparation. Adult male Sprague-Dawley rats fed ad libitum were used as liver donors. ECs and KCs were isolated by a modification of the method of Nagelkerke (33) using collagenase perfusion, differential centrifugation, and centrifugal elutriation with a JE-6B rotor in a $\mathrm{J} 2$ -
$21 \mathrm{M} /$ E centrifuge (Beckman Instruments, Inc., Fullerton, CA). The liver was initially perfused with $500 \mathrm{~cm}^{3}$ of solution I $(0.12 \mathrm{M} \mathrm{NaCl}, 24 \mathrm{mM}$ $\mathrm{NaHCO}_{3}, 10 \mathrm{mM}$ glucose, $50 \mathrm{mM} \mathrm{KCl}, 12 \mathrm{mM} \mathrm{MgSO}{ }_{4} \cdot 7 \mathrm{H}_{2} \mathrm{O}, 0.5 \mathrm{mM}$

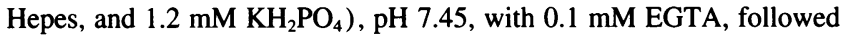
by perfusion with $200 \mathrm{~cm}^{3}$ of solution I with $0.9 \mathrm{mM} \mathrm{CaCl}_{2}$, and 75 $\mathrm{mg}$ of collagenase $\mathrm{P}$ (Boehringer Mannheim Biochemicals, Indianapolis, IN) at $20 \mathrm{~cm}^{3} / \mathrm{min}$. The liver lobes were then removed and minced in $400 \mathrm{~cm}^{3}$ of solution I, and the resultant cell suspension was filtered through nylon mesh (Tetko Co., Briarcliff Manor, NY) and incubated for $30 \mathrm{~min}$ with $300 \mathrm{mg}$ of pronase (Boehringer Mannheim Biochemicals) and $0.5 \mathrm{mM}$ dithiothreitol (DTT). The cells were then spun at 50 $g$ for $1 \mathrm{~min}$ and resuspended in $10 \mathrm{~cm}^{3}$ of Krebs solution $(0.12 \mathrm{M} \mathrm{NaCl}$,

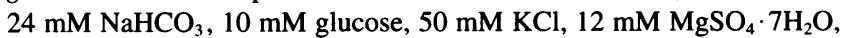

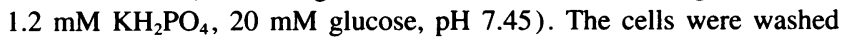
two more times, and the supernatants were saved from each spin.

The supernatants from the washings above were centrifuged at 500 $g$ for $10 \mathrm{~min}$, the supernatants were discarded, and the pellet was resuspended in $10 \mathrm{~cm}^{3}$ of Krebs solution. This pellet contained mostly nonparenchymal cells. These cells were counted, and their viability was assessed by trypan blue exclusion. The cells were then elutriated at a rotor speed of $2,500 \mathrm{rpm}$ at $4^{\circ} \mathrm{C}$. The flow rates for the isolation of the various cell types were as follows: ECs $24 \mathrm{~cm}^{3} / \mathrm{min}$, ECs plus $\mathrm{KCs} 35 \mathrm{~cm}^{3} /$ $\min , \mathrm{KCs} 46 \mathrm{~cm}^{3} / \mathrm{min}$, and HEPs with the rotor off.

HEPs were prepared using the above procedure without the use of pronase. Since cell purity was high and viability was superior without elutriation, subsequent preparations were done by differential centrifugation alone. XOD/XDH activity was similar in viable elutriated and nonelutriated hepatocytes.

Cell purity was assessed by $(a)$ visual inspection; $(b)$ measurement of pyruvate kinase isozymes to differentiate nonparenchymal cells (type M) from HEPs and hepatocellular debris (type L); and (c) peroxidase staining to differentiate KCs from ECs (nonstaining). Pyruvate kinase isozymes were measured spectrophotometrically with or without fructose (34). Peroxidase staining was performed as per Widmann (35) with a 20 -min incubation at $37^{\circ} \mathrm{C}$ in $50 \mathrm{mM}$ Tris/ $\mathrm{HCl}(\mathrm{pH} \mathrm{7.35})+7 \%$ sucrose $+0.1 \%$ diamino benzidine $+0.1 \% \mathrm{H}_{2} \mathrm{O}_{2}$. Additionally, ECs and $\mathrm{KCs}$ were distinguished by their ability to bind fluorescently labeled acetylated low density lipoprotein (Biomedical Technologies, Inc., Stoughton, MA). The purity of the cell fractions as determined by these methods was $>95 \%$ for the HEPs, and $>90 \%$ for the ECs and KCs (36).

Cell incubations. The isolated HEPs, ECs, and KCs were washed twice in $20 \mathrm{~cm}^{3}$ of Krebs solution to remove the DTT before incubation for the specified intervals $\left(60,90\right.$, and $150 \mathrm{~min}$ at $37^{\circ} \mathrm{C} ; 8,16$, or $24 \mathrm{~h}$ at $4^{\circ} \mathrm{C}$ ) in a hypoxic Krebs solution at 2 million cells $/ \mathrm{cm}^{3}$ for the HEPs, 5 million cells $/ \mathrm{cm}^{3}$ for the KCs, and 10 million cells $/ \mathrm{cm}^{3}$ for the ECs. All incubations were accompanied by gentle shaking. After the incubations were complete, the cells were spun down $(50 \mathrm{~g}$ for $1 \mathrm{~min}$ for the HEPs, and $500 \mathrm{~g}$ for $10 \mathrm{~min}$ for the ECs and KCs) and transferred to a phosphate buffer ( $\mathrm{pH} 7.8$ ) containing $0.05 \mathrm{M}$ potassium phosphate, 1.0 mM EDTA, 0.2 mM PMSF (to inhibit irreversible XDH to XOD conversion), and $0.5 \mathrm{mM}$ DTT (to inhibit reversible XDH to XOD conversion). For cell injury studies, KCs were spun down after $16 \mathrm{~h}$ of cold hypoxia and then resuspended in oxygen or nitrogen (control) saturated Krebs buffer at $37^{\circ} \mathrm{C}$ with or without $100 \mu \mathrm{M}$ allopurinol.

Enzyme purification. The resultant cell suspensions were sonicated (50 Sonic Dismembrator; Fisher Scientific Co., Pittsburgh, PA) and spun at $27,000 \mathrm{~g}$ for $30 \mathrm{~min}$. The supernatant was passed through a Sephadex G-25 column (Pharmacia Fine Chemicals, Uppsala, Sweden) to remove any endogenous inhibitors or substrates and was assayed immediately.

$X O D / X D H$ assays. The eluate was assayed for XDH and XOD activity using a micromodification of the method of Waud and Rajagopalan $(19,37)$. Uric acid formation was measured spectrophotometrically at $295 \mathrm{~nm}$ with $(\mathrm{XOD}+\mathrm{XDH})$ or without (XOD) $1 \mathrm{mM} \mathrm{NAD}^{+}$at $25^{\circ} \mathrm{C}$. Percent XOD activity was expressed as the rate of formation of uric acid without $\mathrm{NAD}^{+}$divided by the rate with $\mathrm{NAD}^{+}$. In the experiments where conformationally altered XOD activity (XODc) was mea- 


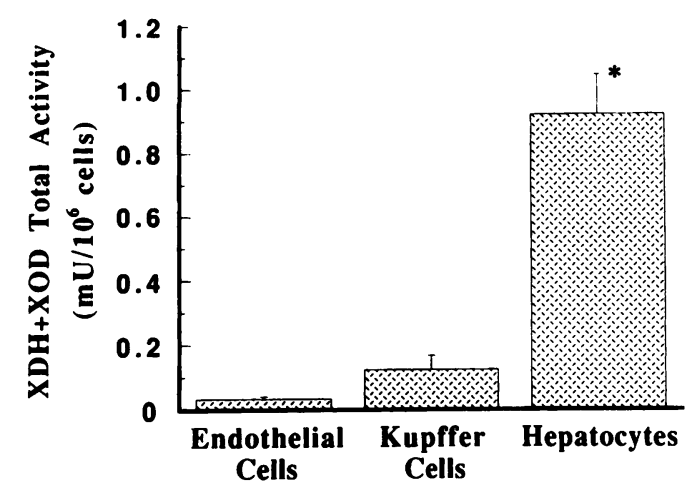

Figure 1. Cellular distribution of XOD + XDH activity in the liver. Livers from fed rats were separated into purified populations of ECs, $\mathrm{KCs}$, and HEPs and then assayed for total XOD + XDH activity ( $\mathrm{mU} /$ $10^{6}$ cells). The mean $\pm \mathrm{SE}$ for five or more experiments per group are shown. $* P<0.01$ compared with ECs or KCs.

sured, the cells were transferred to a phosphate buffer without DTT. XODc activity was calculated as the difference in XOD activity in the same cell preparation with (XODe) and without (XODe + XODc) DTT. Protein content was quantified using the Lowry protein determination with BSA as a standard (38).

Statistics. All assays were run in duplicate or triplicate, and data are expressed as mean \pm SEM. Data were analyzed using an analysis of variance followed by Fischer's least significant difference test for paired data (SYSTAT for Windows). A probability of $<0.05$ was considered statistically significant.

\section{Results}

Determination of $X O D+X D H$ cellular and specific activities in isolated HEPs, ECs, and KCs. Enzymatic activity on a cellular basis (Fig. 1) was much greater in the HEPs $(0.92 \pm 0.12$ $\mathrm{mU} / 10^{6}$ cells; $\left.P<0.01\right)$ than in the KCs $\left(0.12 \pm 0.04 \mathrm{mU} / 10^{6}\right.$ cells) or ECs $\left(0.03 \pm 0.01 \mathrm{mU} / 10^{6}\right.$ cells $)$. However, all three cell types had similar specific activities. The XOD + XDH specific activity was highest in the KCs $(2.30 \pm 0.22)$, followed by the HEPs $(1.85 \pm 0.10 \mathrm{U} / \mathrm{g}$ protein $)$ and ECs $(1.69 \pm 0.54$ $\mathrm{U} / \mathrm{g}$ protein).

Conversion to XOD activity during hypoxia in three isolated hepatic cell types. To determine whether conversion from XDH to XOD during hypoxia occurs at different rates within HEPs, $\mathrm{ECs}$, or $\mathrm{KCs}$, experiments were performed incubating purified cells for various intervals at 37 or $4^{\circ} \mathrm{C}$ in a nitrogen-saturated Krebs solution. As depicted in Fig. 2, percent XOD activity increased in all three cell types at $37^{\circ} \mathrm{C}$ over 150 min of hypoxia. The rates of increase in the HEPs and ECs were similarly low with linear increases in percent XOD activity from initial values of $29 \pm 2$ and $21 \pm 2 \%$, respectively, to $38 \pm 3$ and $39 \pm 3 \%$ XOD activity after $150 \mathrm{~min}$ of hypoxia. XOD activity increased much more rapidly in the KCs. Although initial percent XOD activity was similar to the other cell types ( $28 \pm 3 \%)$, it was significantly higher $(P<0.05)$ after only 90 min of hypoxia, and after 150 min of warm hypoxia the KCs had converted to $91 \pm 7 \%$ oxidase activity, nearly double that of the other two cell types.

Similar results were found for hypoxic incubation at $4^{\circ} \mathrm{C}$ (Fig. 3). HEPs and ECs converted slowly to $49 \pm 2$ and $49 \pm 5 \%$ XOD, respectively, after $24 \mathrm{~h}$. KC percent XOD activity was significantly greater than that of the other cell types after only

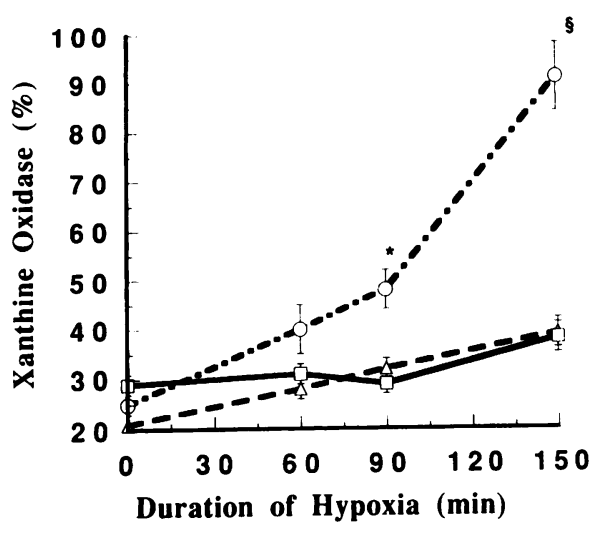

Figure 2. Conversion to XOD activity during warm hypoxia in isolated ECs, KCs, and HEPs. Cells were isolated using countercurrent elutriation and incubated in nitrogen-saturated Krebs solution at $37^{\circ} \mathrm{C}$ for the specified intervals. Each point represents the mean $\pm \mathrm{SE}$ of the percent XOD activity $[\mathrm{XOD} /(\mathrm{XOD}+\mathrm{XDH})]$ for four or more preparations of ECs (triangles), KCs (circles), or HEPs (squares). $* P<0.01$ versus ECs or HEPs; ${ }^{\S} P \leq 0.005$ versus ECs or HEPs.

$8 \mathrm{~h}$ of cold incubation $(P<0.05)$. After $24 \mathrm{~h}, \mathrm{KC} \mathrm{XDH}$ was almost entirely converted to XOD activity $(94 \pm 4 \%)$.

Changes in specific activity. Since we have adopted the widely used convention of expressing conversion from $\mathrm{XDH}$ to XOD activity as XOD/XOD + XDH $(13,18,20,39)$, the data presented above do not exclude the possibility that decreases in $\mathrm{XDH}$ activity alone contributed to the increase in percent $\mathrm{XOD}$ activity. However, as shown for $\mathrm{KC}$ enzyme activity during cold hypoxia, the total XOD + XDH specific activity did not change significantly throughout the duration of the experiment (Fig. 4). XDH specific activity decreased throughout the incubation period, matched by increases in XOD specific activity. Thus the increase in percent XOD activity was due entirely to conversion from the dehydrogenase to oxidase form, not to a decrease in dehydrogenase activity.

Determination of DTT-labile activity. Since the homogenization buffer contained DTT, the results reported thus far have

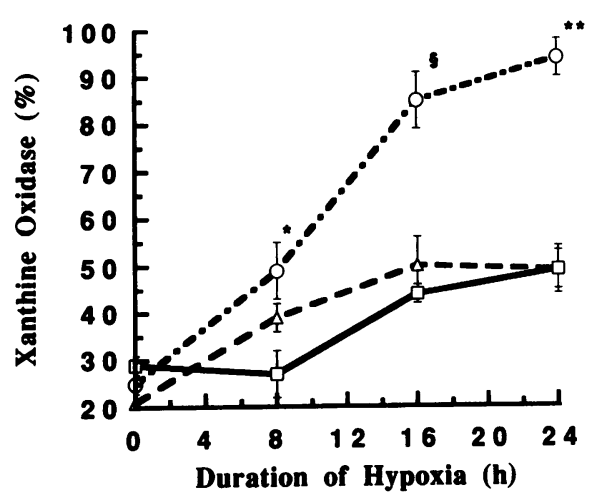

Figure 3. Conversion to XOD activity during cold hypoxia in isolated ECs, KCs, and HEPs. Cells were isolated using countercurrent elutriation and incubated in nitrogen-saturated Krebs solution at $4^{\circ} \mathrm{C}$ for the specified intervals. Each point represents the mean $\pm \mathrm{SE}$ of the percent $\mathrm{XOD}[\mathrm{XOD} /(\mathrm{XOD}+\mathrm{XDH})]$ activity for five preparations of ECs (triangles), $\mathrm{KCs}$ (circles), or HEPs (squares). $* P<0.05$ versus ECs or HEPs; $\quad{ }^{\S} P<0.005$ versus ECs or HEPs; $\quad * * P<0.001$ versus ECs or KCs. 


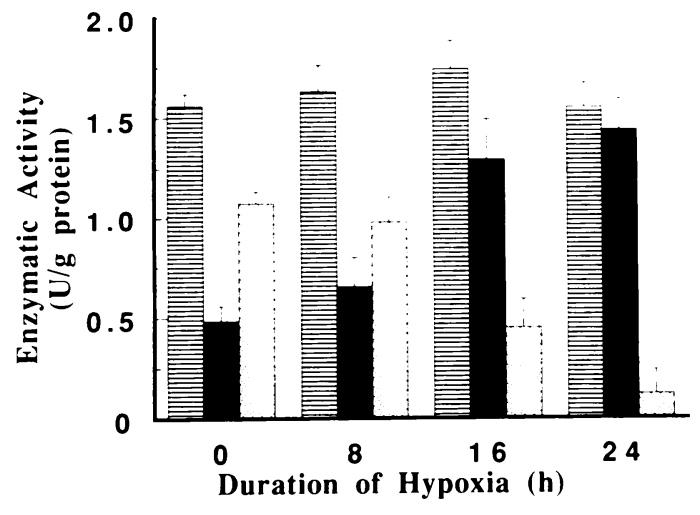

Figure 4. Changes in XOD, XDH, and XOD plus dehydrogenase specific activities during cold hypoxia in isolated KCs. KCs were isolated using countercurrent elutriation and incubated in nitrogen-saturated Krebs solution at $4^{\circ} \mathrm{C}$ for the specified intervals. XOD $+\mathrm{XDH}$ (horizontal bars), XOD ( gray), and XDH (stippled) specific activities (U/g protein) are plotted as the mean $\pm \mathrm{SE}$ for at least three cell preparations per group.

represented only the $\mathrm{XDH}$ cleavage product with oxidase activity, XODe. However, the XDH molecule may undergo a conformational change to a form with oxidase activity, XODc or DTTlabile XOD $(11,12)$. The physiological importance of XODc is unclear but it may represent the major intermediate for cleavage to XODe $(17,19)$. Since total XOD activity is the sum of both forms, XODc may also be important in oxyradical formation. Therefore, we measured the activity of this form of the enzyme in each cell type during hypoxia. Although XODc activity was negligible in all three cell types at the time of isolation (data not shown), it rose to $41 \pm 6 \%$ in the $\mathrm{KCs}$ after $90 \mathrm{~min}$ of hypoxic incubation at $37^{\circ} \mathrm{C}$, and total XOD activity (XODc $+\mathrm{XODe}$ ) in these cells approached $100 \%$ (Fig. $5 A$ ). In contrast, XODc activity in HEPs and ECs was significantly lower ( $19 \pm 6$ and $7 \pm 3 \%$, respectively; $P<0.01$ ) after the same period of warm hypoxia. After $8 \mathrm{~h}$ of hypoxia at $4^{\circ} \mathrm{C}$, the KC XODc rose to high levels $(35 \pm 7 \%)$, with total XOD $>80 \%$. There was little XODc formation in either the ECs $(4 \pm 5 \%)$ or HEPs $(2 \pm 3 \%)$ at this time (Fig. $5 B$ ). Thus, conversion from $\mathrm{XDH}$ to XOD activity in the KCs was near completion after only 90 min of warm or $8 \mathrm{~h}$ of cold hypoxia.

$K C$ viability and conversion to XOD. To determine whether the conversion of XDH to XOD was occurring within live cells, cell viability, as quantified by trypan blue exclusion, was measured at each time point along with $\mathrm{XOD} / \mathrm{XDH}$ activity. The conversion to high XOD activity during cold hypoxia in KCs took place with only small changes in cell viability (Fig. 6). Similarly, after $90 \mathrm{~min}$ of warm hypoxia, total XOD activity (XODc + XODe) was $89 \pm 5 \%$ and $\mathrm{KC}$ viability was $89 \pm 3 \%$. Thus, near complete conversion to the oxidase form took place in $\mathrm{KCs}$ during warm and cold hypoxia without a marked decrease in cell viability. $\mathrm{KC}$ viability after $16 \mathrm{~h}$ of cold hypoxia ( $67 \pm 4 \%$ trypan blue negative, $n=4$ ) was markedly decreased after $30 \mathrm{~min}(31 \pm 4 \%, P<0.01)$ and $60 \min (9 \pm 4 \%, P<0.01)$ of reoxygenation at $37^{\circ} \mathrm{C}$. However, the addition of $100 \mu \mathrm{M}$ allopurinol ( $76 \pm 4 \%$ after $16 \mathrm{~h}$ cold hypoxia, $n=4$ ) reduced this reoxygenation injury at both time points $(45 \pm 4$ and $29 \pm 4 \%$, respectively; $P<0.05$ versus allopurinol group) to levels similar to warm hypoxic controls ( $42 \pm 5$ and $33 \pm 11 \%$ ).
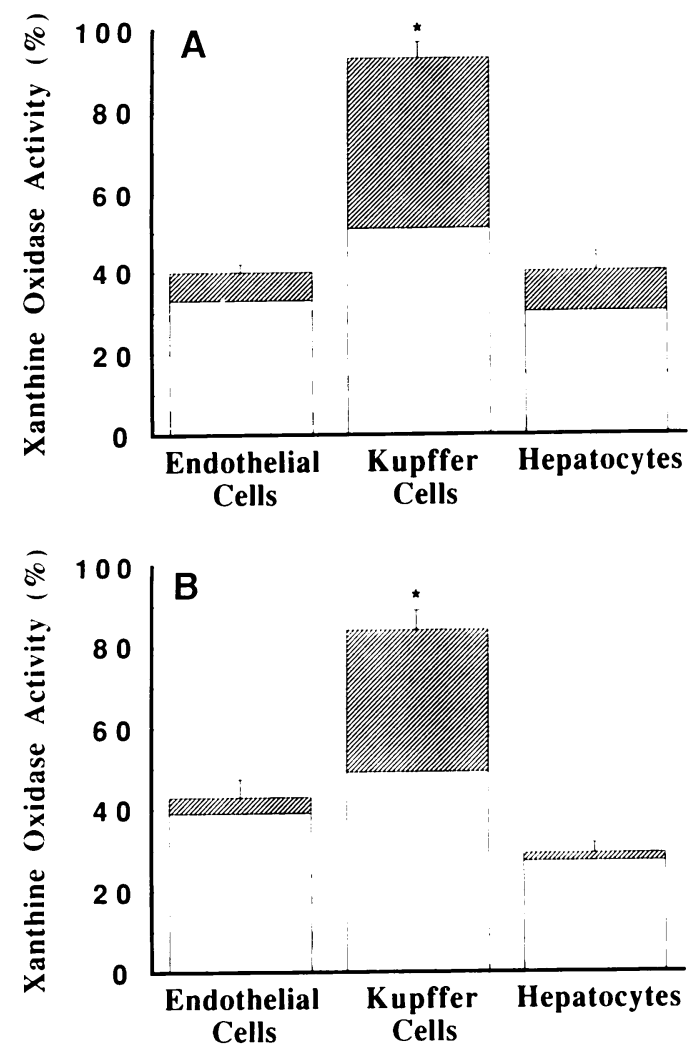

Figure 5. Effect of warm or cold hypoxia on reversible XOD activity (XODc) in isolated ECs, KCs, and HEPs. Cells were isolated using countercurrent elutriation and incubated in nitrogen-saturated Krebs solution at $(A) 37^{\circ} \mathrm{C}$ for $90 \mathrm{~min}$ or $(B) 4^{\circ} \mathrm{C}$ for $8 \mathrm{~h}$. In each group, cells were divided equally and assayed for XOD and XDH activities in the presence or absence of the sulfhydryl protectant DTT. Reversible or DTT-labile XOD activity (XODc) was calculated as the difference between percent XOD measured in the absence (XODe + XODc) or presence (XODe) of DTT. XODc (stippled area), XODe (unfilled area), and their sum are plotted as mean \pm SE for five cell preparations in each group. $* P<0.01$ compared with EC or HEP XODc.

\section{Discussion}

The XOD theory of reperfusion injury proposes that the conversion of XDH to XOD during ischemia is the underlying mechanism for subsequent free radical formation and injury during reperfusion (40). This theory gained substantial support primarily through indirect evidence; allopurinol, an XOD inhibitor, is effective in diminishing reperfusion injury in a number of experimental systems (14-16, 41-44). Since Roy and McCord's initial work (13), several investigators have reported relatively slow rates of conversion of $\mathrm{XDH}$ to $\mathrm{XOD}$ in the liver (17, 18) and gut (39). These findings suggest that the conversion to XOD takes place in a time course too slow for its purported role in mediating reperfusion injury. Although we have reported previously on physiologic interventions (starvation, in vivo ischemia) that accelerate XOD formation in the hypoxic liver (19), it is still unclear whether changes in hepatic XOD can occur within a time frame consistent with its theorized role in initiating reperfusion injury. In recent years, several researchers have questioned the role of XOD in mediating hepatic reperfusion injury $(45,46)$, however, XOD still plays a 


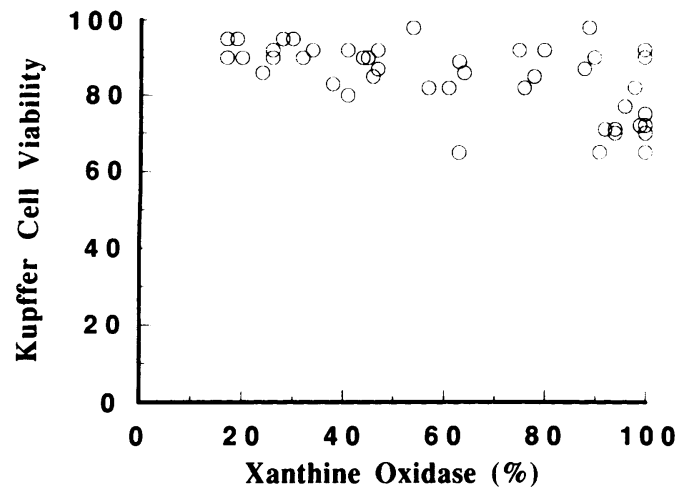

Figure 6. Relationship between KC viability and conversion to XOD activity during cold hypoxia. KCs were isolated using countercurrent elutriation and incubated in nitrogen-saturated Krebs solution at $4^{\circ} \mathrm{C}$. Cells were sampled at $0,8,16$, and $24 \mathrm{~h}$. Cell viabilities were measured by trypan blue exclusion. Each point represents the percent XOD activity (XODe) and viability from one cell preparation at one time point.

central role in the more recently advanced "no-flow" theory of reperfusion injury $(9,10)$.

Given the number of recent observations pointing to the importance of nonparenchymal cells in mediating hepatic preservation and reperfusion injury (24-26), we decided to reinvestigate the role of XOD in reperfusion injury by measuring XOD formation during hypoxia in purified populations of HEPs, ECs, and KCs. This approach has allowed us to answer the three central unresolved questions regarding XOD and liver injury: (a) in which cell type is this enzyme localized; $(b)$ what is the time course of enzyme conversion within each cell type; and (c) does significant $\mathrm{XDH}$ to XOD conversion occur within viable cells?

We found XOD + XDH activity on a per cell basis to be much greater in HEPs than in either ECs or KCs (Fig. 1). This was not surprising given the much larger cell volume and protein content of these cells. However, the nonparenchymal cells and HEPs had similar XDH + XOD specific activities. Therefore, ECs and the KCs possess significant, potentially physiologically important XDH + XOD levels. This direct measurement of XOD $+\mathrm{XDH}$ activity in the liver contrasts with the histochemical data available $(27,29-31)$ primarily by demonstrating the potential importance of KC XOD activity, which has not been reported previously.

Since HEPs are the dominant cell type in the liver in terms of size, number, and protein content ( $>90 \%$ liver protein), enzymatic changes in the nonparenchymal cells may be missed when measuring XOD activity in the whole organ. Therefore, we decided to study the time course of XDH to XOD conversion in purified populations of nonparenchymal cells and HEPs. XOD formation was relatively slow in isolated HEPs and ECs during warm hypoxia (Fig. 2). The rate of conversion in isolated HEPs was similar to the rate we reported previously in whole liver. After $150 \mathrm{~min}$ of hypoxia, isolated HEPs had $38 \pm 3 \%$ XOD activity. This figure corresponds well to the $40 \%$ XOD activity we found in the entire liver after the same period of hypoxia (19). This suggests that results from our isolated cell model may reflect changes in the intact liver, since our cell isolation procedure produced no evident increase in the rate of XOD conversion in isolated HEPs compared with that of the entire organ.
During hypoxic incubation, XOD activity rose dramatically faster in KCs than in HEPs or ECs (Fig. 2) with slower but similar rates of XOD accrual during incubation at $4^{\circ} \mathrm{C}$ (Fig. 3 ). These surprising results suggest that KC XOD may be important in hepatic reperfusion injury and that modulation of this activity is likely missed when changes in total organ activity are measured. Several groups $(17,18,47)$, including our own (19), have reported a much slower rate of XDH to XOD conversion in whole liver than we report here for KCs.

The conformationally altered form of the XDH molecule with oxidase activity (XODc) is formed from the oxidation of several of the 14 sulfhydryl groups of XDH (37). This form is believed to precede cleavage to the smaller molecule, XODe $(17,19)$. The present data support this theory since increases in $\mathrm{KC}$ XODc seemed to precede conversion to XODe. When total XOD activity (XODc + XODe) is considered, most of the enzyme in KCs was in this free radical-producing state after only $90 \mathrm{~min}$ of warm or $8 \mathrm{~h}$ of cold hypoxia. This rapid conversion rate is consistent with a role for KC XOD in mediating reperfusion injury in the liver.

Although we adopted the widely used convention of expressing XOD data in relative terms (XOD/XOD + XDH) and demonstrated rapid changes in percent $\mathrm{XOD}$ activity in $\mathrm{KCs}$ during hypoxia, it is changes in XOD specific activity that are of physiological importance. As displayed in Fig. 4, increases in percent XOD activity in KCs during cold hypoxia did in fact represent parallel increases in XOD specific activity due to conversion from one enzyme form to the other.

If XOD mediates reperfusion injury, increases in XOD activity must occur within living cells during ischemia. We found large changes in XOD activity during cold hypoxia with little change in $\mathrm{KC}$ viability, as measured by trypan blue exclusion (Fig. 6). After $90 \mathrm{~min}$ of warm hypoxia there was conversion to nearly $90 \%$ XOD activity (XODc + XODe) without any significant decrement in cell viability. Similar changes in HEP or EC XOD activity did not occur without large losses of cell viability (data not shown). Although we had previously demonstrated increases in XOD within viable liver tissue (19), the data presented in this paper provide the first direct demonstration of large increases in XOD within live cells in the liver. Although the increases in XOD demonstrated in these studies do not appear to be due to cell death, this observation is limited by the sensitivity of the trypan blue exclusion assay and the ability to clearly define early cell mortality. However, within this limitation there are large increases in XOD activity within viable KCs during either warm or cold hypoxia. The relevance of these findings to reperfusion injury is reflected by our observation that KC death after a brief period of reoxygenation (after $16 \mathrm{~h}$ of cold hypoxia) is blocked by the XOD inhibitor allopurinol. These findings may also explain the observation that KCs are more susceptible to reperfusion injury than hepatocytes (48), since HEPs die an hypoxic death before accumulating large amounts of XOD.

Although the nonparenchymal cells account for only a small amount of the total hepatic protein, XOD conversion in these cell types may be relevant to current theories of hepatic reperfusion injury. Based on data from the cardiac (9) as well as hepatic (49-51) and gut (52) literature it has been proposed that EC-neutrophil interactions mediate reperfusion injury. This "no-reflow" theory suggests that reperfusion injury represents long-term ischemia due to the plugging of capillaries by adherent neutrophils during reperfusion (53). This theory still 
maintains a role for EC XOD as the source of free radicals (54, $55)$ that signal neutrophil chemotaxis $(7,50)$ and adherence to ECs (56) during reperfusion. Thus, allopurinol as well as free radical scavengers appear to inhibit neutrophil infiltration (52). Based on this theory, we expected to find rapid changes in EC XOD during hypoxia. Instead we found more rapid changes in KC XOD activity. Since KCs also line the lumen of the hepatic sinusoids, free radicals generated by these cells may also act as chemical messengers for neutrophil chemotaxis and other signaling events.

Recent data have suggested that $\mathrm{KC}$ free radical generation may mediate hepatic reperfusion injury $(57,58)$. KC inactivators, such as methyl palmitate, have been shown to significantly protect the liver from oxidative ischemia-reperfusion injury (59). In our own model of cold liver preservation and reperfusion, we have found that oxyradical production is primarily a KC-mediated event (60). The idea that KCs may mediate hepatocellular injury is not novel as there are both old (61) and new data (62) documenting KC/HEP interactions. Additionally, the concept of $\mathrm{KC}$-derived free radicals ( via $\mathrm{XOD}$ ) acting on ECs or HEPs may help explain the large body of data on the amelioration of reperfusion injury by superoxide dismutase (63), a superoxide scavenger which does not readily enter the cell.

Since KC XOD accounts for only a small fraction of that found in the liver, one would expect that XOD-derived oxyradical production during hepatic reperfusion would be relatively modest. This inference is not inconsistent with the theory that XOD-derived oxyradicals from KCs play a major role in hepatic reperfusion injury. Recent data suggest that free radicals formed during reperfusion mediate signal transduction rather than direct oxidative injury $(50,64)$. Therefore, reperfusion injury may be mediated by relatively modest increases in oxyradical production.

In summary, we have demonstrated that ECs and $\mathrm{KCs}$, as well as HEPs, contain significant amounts of XOD $+\mathrm{XDH}$ activity. During hypoxia, there is conversion from $\mathrm{XDH}$ to $\mathrm{XOD}$ in all three cell types. However, the rate of conversion within viable $\mathrm{KCs}$ at either 37 or $4^{\circ} \mathrm{C}$ is markedly faster than that of ECs or HEPs. Furthermore, large increases in XOD specific activity occur within viable $\mathrm{KCs}$, and cell death accompanying the reoxygenation of such cells is blocked by the XOD inhibitor allopurinol. This is the first direct evidence that significant conversion to XOD activity can occur in living cells in the liver within the time constraints of observed ischemia-reperfusion injury. These data may explain the discrepancy between the effects of the XOD inhibitor allopurinol in ameliorating reperfusion injury and the relatively slow rates of XDH to XOD conversion reported in the (whole) liver. Further studies directed toward understanding the modulation of $\mathrm{KC}$ XOD activity and the physiologic effects of oxyradicals generated by the $\mathrm{KCs}$ during reperfusion should aid in further defining the mecha$\operatorname{nism}(\mathrm{s})$ of hepatic reperfusion injury.

\section{Acknowledgments}

The experiments reported herein were conducted according to the principles set forth in the "Guide to the Care and Use of Laboratory Animals," Institute of Animal Resources, National Research Council.

This study was supported in part by a Veterans Administration Merit Review Award. C. A. Brass was the Hans Popper Liver Scholar of the American Liver Foundation (1990-1993). J. S. Wiezorek and D. H.
Brown were recipients of American Gastroenterology Association summer student fellowship awards.

\section{References}

1. Liver waiting list data. 1994. UNOS Update. 10:19.

2. Mora, N. P., G. B. Klintmalm, J. B. Cofer, S. S. Poplawski, R. M. Goldstein, T. A. Gonwa, and B. S. Husberg. 1990. Results after liver retransplantation (RET): a comparative study between "elective" or "nonelective"' RET. Transplant. Proc. 22:1509-1511.

3. Walsh, T. R., P. N. Rao, L. Makowka, and T. E. Starzl. 1990. Lipid peroxidation is a nonparenchymal cell event with reperfusion after prolonged liver ischemia. J. Surg. Res. 49:18-22.

4. Davies, K. J. 1987. Protein damage and degradation by oxygen radicals. I. General aspects. J. Biol. Chem. 262:9895-9901.

5. Girotti, A. W., J. P. Thomas, and J. E. Jordan. 1986. Xanthine oxidasecatalyzed crosslinking of cell membrane proteins. Arch Biochem. Biophys. 251:639-653.

6. Petrone, W. F., D. K. English, K. Wong, and J. M. McCord. 1980. Free radicals and inflammation: the superoxide dependent activation of neutrophil chemotactic factor in plasma. Proc. Natl. Acad. Sci. USA. 77:1159-1163.

7. Brass, C. A., F. A. Nunes, and R. Nagpal. 1995. Increased oxyradical production during reoxygenation of perfused rat liver: signal vs. injury. Transplantation (Baltimore). In press.

8. Zimmerman, B. J., M. B. Grisham, and D. N. Granger. 1990. Role of oxidants in ischemia/reperfusion-induced granulocyte infiltration. Am. J. Physiol. 258:G185-190.

9. Engler, R. G., M. D. Dahlgren, D. D. Morris, M. A. Peterson, and G. W. Schmid-Schonbein. 1986. Role of leukocytes in response to acute myocardial ischemia and reflow in dogs. Am. J. Physiol. 251:H314-H322.

10. Granger, D. M., P. R. Kvietys, and M. A. Perry. 1993. Leukocyte-endothelial cell adhesion induced by ischemia and reperfusion. Can. J. Physiol. Pharmacol. $71: 67-75$

11. Waud, W. R. and K. V. Rajagopalan. 1976. The mechanism of conversion of rat liver xanthine dehydrogenase from an $\mathrm{NAD}^{+}$-dependent form (type $\mathrm{D}$ ) to an $\mathrm{O}_{2}$-dependent form (type O). Arch. Biochem. Biophys. 172:365-379.

12. Clare, D. A., B. A. Blakistone, H. E. Swaisgood, and H. R. Horton. 1981. Sulfhydryl oxidase-catalyzed conversion of xanthine dehydrogenase to xanthine oxidase. Arch. Biochem. Biophys. 211:44-47.

13. Roy, R. S., and J. M. McCord. 1983. Superoxide and ischemia: conversion of xanthine dehydrogenase to xanthine oxidase. In Oxyradicals and Their Scavenger Systems. Vol. II. Cellular and Medical Aspects. R. A. Greenwald and G. Cohen, editors. Elsevier Science Publishers B. V., Amsterdam. 145-153.

14. Marotto, M. E., R. G. Thurman, and J. J. LeMasters. 1988. Early midzonal cell death during low-flow hypoxia in the isolated, perfused rat liver: protection by allopurinol. Hepatology 8:585-590.

15. Karwinski, W., M. Farstad, R. Ulvik, and O. Soreide. 1991. Sixty-minute normothermic liver ischemia in rats: evidence that allopurinol improves liver cell energy metabolism during reperfusion but that timing of drug administration is important. Eur. Surg. Res. 22:27-33.

16. Zhong, Z., J. J. Lemasters, and R. G. Thurman. 1989. Role of purines and xanthine oxidase in reperfusion injury in perfused rat liver. J. Pharmacol. Exp. Ther. 250:470-475.

17. McKelvey, T. G., M. E. Hollwarth, D. N. Granger, T. D. Engerson, U. Landler, and H. P. Jones. 1988. Mechanisms of conversion of xanthine dehydrogenase in ischemic rat liver and kidney. Am. J. Physiol. 254:G753-G760.

18. Engerson, T. D., T. G. McKelvey, D. B. Rhyne, E. B. Boggio, S. J. Snyder, and H. P. Jones. 1987. Conversion of xanthine dehydrogenase to oxidase in ischemic rat tissues. J. Clin. Invest. 79:1564-1570.

19. Brass, C. A., J. Narciso, and J. L. Gollan. 1991. Enhanced activity of the free radical producing enzyme xanthine oxidase in hypoxic rat liver. Regulation and pathophysiologic significance. J. Clin. Invest. 87:424-431.

20. Parks, D., and D. N. Granger. 1986. Xanthine oxidase: biochemistry, distribution and physiology. Acta Physiol. Scand. 548(Suppl.):87-99.

21. Lemasters, J. J., and R. G. Thurman. 1993. Hypoxia and reperfusion injury to liver. Prog. Liver Dis. 11:85-114.

22. Caldwell-Kenkel, J. C., R. T. Currin, Y. Tanaka, R. G. Thurman, and J. J. LeMasters. 1990. Kupffer cell activation, endothelial cell damage, and lysosomal enzyme release in rat liver after cold ischemic storage in Euro-Collins solution or UW solution. Gastroenterology. 98:A574. (Abstr.)

23. Holloway, C. M., P. R. Harvey, and S. M. Strasberg. 1990. Viability of sinusoidal lining cells in cold-preserved rat liver allografts. Transplantation (Baltimore). 49:225-229.

24. Jaeschke, H., and A. Farhood. 1993. Neutrophil and Kupffer cell-induced oxidant stress and ischemia-reperfusion injury in rat liver. Am. J. Physiol. 260:G355-G362

25. Rymsa, B., J. F. Wang, and H. De Groot. 1991. $\mathrm{O}_{2}$-release by activated Kupffer cells upon reoxygenation. Am. J. Physiol. 261:G602-G607. 
26. Caldwell-Kenkel, J. C., R. T. Currin, Y. Tanaka, R. G. Thurman, and J. J. Lemasters. 1989. Reperfusion injury to endothelial cells following cold ischemic storage of rat livers. Hepatology. 10:292-299.

27. Jarasch, E. D., C. Grund, G. Bruder, H. W. Heid, T. W. Keenan, and W. W. Franke. 1981. Localization of xanthine oxidase in mammary gland epithelium and capillary endothelium. Cell. 25:67-82.

28. Kooij, A., W. M. Frederiks, R. Gossrau, and C. J. F. Van Noorden. 1991. Localization of xanthine oxidoreductase activity using the tissue protectant polyvinyl alcohol and final electron acceptor tetranitro BT. J. Histochem. Cytochem. 39:87-93.

29. Holmes, R. S., and J. L. Vandeberg. 1986. Aldehyde dehydrogenases, aldehyde oxidase and xanthine oxidase from baboon tissues: phenotypic variability and subcellular distribution in liver and brain. Alcohol. 3:205-214.

30. Auscher, C. N., and N. Amory. 1976. The histochemical localization of xanthine oxidase in the rat liver. Biomedicine (Paris). 25:37-38.

31. Hashimoto, S. 1974. The developmental changes in rat liver xanthine oxidase(s) and its intracellular distribution. Agric. Biol. Chem. 38:1697-1702.

32. Angermuller, S., G. Bruder, A. Volkl, H. Wesch, and H. Fahimi. 1987. Localization of xanthine oxidase in crystalline cores of peroxisomes: a cytochemical and biochemical study. Eur. J. Cell Biol. 45:137-144.

33. Nagelkerke, J. F., K. P. Barto, and T. J. C. van Berkel. 1983. In vivo and in vitro uptake and degradation of acetylated low density lipoprotein by rat liver endothelial, Kupffer, and parenchymal cells. J. Biol. Chem. 258:12221-12227.

34. van Berkel, T. J. C., J. F. Koster, and W. C. Hulsmann. 1972. Distribution of L- and M-type pyruvate kinase between parenchymal and Kupffer cells of rat liver. Biochem. Biophys. Acta. 276:425-429.

35. Widmann, J.-J., R. S. Cotran, and H. D. Fahimi. 1972. Mononuclear phagocytes (Kupffer cells) and endothelial cells: identification of two functional cell types in rat liver sinusoids by endogenous peroxidase activity. J. Cell Biol. 52:159-170.

36. Brass, C. A., and M. G. Mody. 1995. Localization of purine nucleoside phosphorylase in the rat liver: marker for endothelial cell injury? Hepatology. In press.

37. Waud, W. R., and K. V. Rajagopalan. 1976. Purification and properties of the $\mathrm{NAD}^{+}$dependent (type $\mathrm{D}$ ) and $\mathrm{O}_{2}$ dependent (type $\mathrm{O}$ ) forms of rat liver xanthine dehydrogenase. Arch. Biochem. Biophys. 172:354-356.

38. Lowry, O. H., N. J. Rosebrough, A. L. Farr, and R. J. Randall. 1951. Protein measurement with the Folin phenol reagent. J. Biol. Chem. 193:265-275.

39. Parks, D. A., T. K. Williams, and J. S. Beckman. 1988. Conversion of xanthine dehydrogenase to oxidase in ischemic rat intestine: a reevaluation. Am. J. Physiol. 25:G768-G774.

40. McCord, J. M. 1985. Oxygen derived free radicals in post-ischemic tissue injury. N. Engl. J. Med. 312:159-163.

41. Owens, M. L., M. L. Harrison, M. W. Wolcott, J. G. Maxwell, and J. B. Taylor. 1974. Allopurinol and hypoxanthine pretreatment of canine kidney donors. Transplantation (Baltimore). 17:424-427.

42. Parks, D. A., and D. N. Granger. 1983. Ischemia-induced vascular changes: role of xanthine oxidase and hydroxyl radicals. Am. J. Physiol. 245 (Gastrointest. Liver Physiol. 8):G285-G289.

43. Brown, J. M., L. S. Terada, M. A. Grosso, G. J. Whitmann, S. E. Velasco, A. Patt, A. H. Harken, and J. E. Repine. 1988. Xanthine oxidase produces hydrogen peroxide which contributes to reperfusion injury of ischemic, isolated, perfused rat hearts. J. Clin. Invest. 81:1297-1301.

44. Im, M. J., J. E. Hoopes, Y. Yoshimura, P. N. Manson, and G. B. Bulkley. 1989. Xanthine: acceptor oxidoreductase activities in ischemic rat skin flaps. $J$. Surg. Res. 46:230-234.

45. Jaeschke, H., C. V. Smith, and J. R. Mitchell. 1988. Reactive oxygen species during ischemia-reflow injury in isolated perfused rat liver. J. Clin. Invest. 81:1240-1246.
46. Metzger, J., and B. H. Lauterburg. 1988. Effect of allopurinol on oxidant stress and hepatic function following ischemia and reperfusion in the rat. Liver. 8:344-349.

47. Marubayashi, S., K. Dohi, K. Yamada, and T. Kawasaki. 1991. Role of conversion of xanthine dehydrogenase to oxidase in ischemic rat liver cell injury. Surgery (St. Louis). 110:537-543.

48. Rymsa, B., H. D. Becker, W. Lauchart, and H. de Groot. 1990. Hypoxia/ reoxygenation injury in liver: Kupffer cells are much more vulnerable to reoxygenation than to hypoxia. Res. Commun. Chem. Pathol. Pharmacol. 68:263-266.

49. Koo, A., H. Komatsu, G. Tao, M. Inoue, P. H. Guth, and N. Kaplowitz. 1992. Contribution of no-reflow phenomenon to hepatic injury after ischemiareperfusion: evidence for a role for superoxide anion. Hepatology. 15:507-514.

50. Jaeschke, J., A. Farhood, and C. W. Smith. 1990. Neutrophils contribute to ischemia/reperfusion injury in rat liver in vivo. FASEB (Fed. Am. Soc. Exp. Biol.) J. 4:3355-3359.

51. Takei, Y., I. Marzi, W. Gao, G. J. Gores, J. J. Lemasters, and R. G. Thurman. 1991. Leukocyte adhesion and cell death following orthotopic liver transplantation in the rat. Transplantation (Baltimore). 51:959-965.

52. Grishham, M. B., L. A. Hernandez, and D. N. Granger. 1986. Xanthine oxidase and neutrophil infiltration in intestinal ischemia. Am. J. Physiol. 251:G567-G574.

53. Engler, R. G., M. D. Dahlgren, D. D. Morris, M. A. Peterson, and G. W. Schmid-Schonbein. 1986. Role of leukocytes in response to acute myocardial ischemia and reflow in dogs. Am. J. Physiol. 251:H314-H322.

54. Zweier, J. L., P. Kuppusamy, and G. A. Lutty. 1988. Measurement of endothelial cell free radical generation: evidence for a central mechanism of free radical injury in post-ischemic tissues. Proc. Natl. Acad. Sci. USA. 85:40464050 .

55. Ratych, R. E., R. S. Chuknyiska, and G. B. Bulkley. 1987. The primary localization of free radical generation after anoxia/reoxygenation in isolated endothelial cells. Surgery (St. Louis). 102:122-131.

56. Linas, S. L., P. F. Shanley, D. Whittenburg, E. Berger, and J. E. Repine. 1988. Neutrophils accentuate ischemia-reperfusion in isolated perfused rat kidney. Am. J. Physiol. 255:F728-F735.

57. Jaeshke, H., and A. Farhood. 1991. Neutrophil and Kupffer cell-induced oxidant stress and ischemia-reperfusion injury in the rat liver. Am. J. Physiol. 260:G355-G362.

58. Caldwell-Kenkel, J. C., R. T. Currin, Y. Tanaka, R. G. Thurman, and J. J. Lemasters. 1991. Kupffer cell activation and endothelial cell damage after storage of rat livers: effect of reperfusion. Hepatology. 13:83-95.

59. Marzi, I., K. B. Cowper, Y. Takei, K. A. Lindert, J. J. Lemasters, and R. G. Thurman. 1991. Methyl palmitate prevents Kupffer cell activation and improves survival after orthotopic liver transplantation in the rat. Transplant International. $4: 215-220$.

60. Roberts, T. G., and C. A. Brass. 1993. Hepatic free radical production after cold storage: evidence for Kupffer cell dependent and independent mechanisms. Hepatology. 18:62A. (Abstr.)

61. Kuiper, J., E. Casteleyn, and T. J. C. Van Berkel. 1988. Regulation of liver metabolism by intercellular communication. Adv. Enzyme Regul. 22:193208.

62. Billiar, T. R., R. D. Curran, D. J. Stuehr, F. K. Ferrari, and R. L. Simmons. 1989. Evidence that activation of Kupffer cells results in production of L-arginine metabolites that release cell-associated iron and inhibit hepatocyte protein synthesis. Surgery (St. Louis). 106:364-372.

63. Atalla, S. L., L. H. Toledo-Pereyra, G. H. MacKenzie, and J. P. Cederna. 1985. Influence of oxygen-derived free radical scavengers on ischemic livers. Transplantation (Baltimore). 40:584-589.

64. Jaeschke, H. 1990. Glutathione disulfide as index of oxidant stress in rat liver during hypoxia. Am. J. Physiol. 258:G499-G505. 